\title{
DISCUSSÃO SOBRE AS DIFERENTES ABORDAGENS TEÓRICAS PARA O ESTUDO DAS MIGRAÇÕES E DA MOBILIDADE DO TRABALHO
}

\author{
Vinicius de Paula ISMAEL ${ }^{1}$
}

\begin{abstract}
Resumo
O presente artigo busca trazer uma avaliação a respeito das diferentes concepções teóricas que são assumidas pelos estudos sobre o fenômeno migratório, tendo como fio condutor o desenvolvimento do conceito de mobilidade do trabalho, que é historicamente alinhado ao desenvolvimento do pensamento econômico. Deste modo, dividimos nosso estudo em três tópicos, os quais tratam sobre três distintas abordagens sobre as migrações. Inicialmente analisamos as abordagens clássicas e neoclássicas, que se baseiam na escola econômica do liberalismo e sobretudo em Adam Smith e David Ricardo. No segundo tópico, nosso enfoque se faz sobre a abordagem históricoestrutural e seus avanços em relação ao postulado anterior. Já no terceiro tópico, tratamos sobre a abordagem da mobilidade do trabalho, calcada na análise marxista do modo de produção capitalista e abordada principalmente por Jean-Paul de Gaudemar. Por fim, trazemos algumas reflexões a respeito das abordagens mais recentes sobre as migrações no capitalismo contemporâneo e o papel da geografia nesse panorama.
\end{abstract}

Palavras-chave: Migrações. Mobilidade do trabalho. Trabalho. Geografia humana. Abordagem histórico-estrutural.

\section{DISCUSSION ON DIFFERENT THEORETICAL APPROACHES FOR THE STUDY OF MIGRATION AND LABOR MOBILITY}

\begin{abstract}
This article seeks to bring an analysis regarding the different theoretical conceptions that are assumed by the studies on the migratory phenomenon, having as a guiding thread the development of the concept of labor mobility, which is historically aligned with the development of economic thought. In this way, we divided our study into three topics, which deal with three different approaches to migrations. Initially, we analyzed the classical and neoclassical approaches, which are based on the economic school of liberalism, especially on Adam Smith and David Ricardo efforts. In the second topic, our focus is on the historical-structural approach and its advances in relation to the previous postulate. In the third topic, we deal with the approach of labor mobility, based on the Marxist analysis of the capitalist mode of production and addressed mainly by Jean-Paul de Gaudemar. Finally, we bring some reflections on the most recent approaches to migration in contemporary capitalism and the role of geography in this panorama.
\end{abstract}

\footnotetext{
${ }^{1}$ Mestrando do Programa de Pós-Graduação em Geografia da Universidade Estadual Paulista, UNESP - Campus Rio Claro. E-mail: vinicius.ismael@hotmail.com
} 
Keywords: Migrations. Labor mobility. Work. Human geography. Historicalstructural approach.

\section{DISCUSIÓN SOBRE DIFERENTES ENFOQUES TEÓRICOS PARA EL ESTUDIO DE LA MIGRACIÓN Y LA MOVILIDAD DEL TRABAJO}

\section{Resumen}

El presente artículo busca aportar una analización sobre las diferentes concepciones teóricas que asumen los estudios sobre el fenómeno migratorio, teniendo como hilo conductor el desarrollo del concepto de movilidad laboral, históricamente alineado con el desarrollo del pensamiento económico. De esta manera, dividimos nuestro estudio en tres temas, que abordan tres enfoques diferentes de la migración. Inicialmente, analizamos los enfoques clásicos y neoclásicos, que se basan en la escuela económica del liberalismo y, sobre todo, en Adam Smith y David Ricardo. En el segundo tema, nuestro enfoque está en el enfoque histórico-estructural y sus avances en relación con el postulado anterior. En el tercer tema, tratamos el enfoque de la movilidad laboral, basado en el análisis marxista del modo de producción capitalista y abordado principalmente por Jean-Paul de Gaudemar. Finalmente, le traemos algunas reflexiones sobre los enfoques más recientes de la migración en el capitalismo contemporáneo y el papel de la geografía en este panorama.

Palabras clave: Migraciones. Movilidad del trabajo. Trabajo. Geografía humana. Enfoque histórico-estructural.

\section{INTRODUÇÃ̃}

Desde o período do capitalismo comercial, foram desenvolvidas várias abordagens teóricas sobre as migrações, em especial as relacionando com os sistemas econômicos que predominavam nas sociedades onde foram formuladas tais abordagens (GAUDEMAR, 1977; SALIM, 1992; BECKER, 1997). Além disso, as formas e métodos de estudar as migrações refletem a corrente explicativa predominante daqueles que a desenvolveram e do momento histórico em que foram elaboradas (PELIANO, 1990).

Se pautando na descrição da Organização Internacional para as Migrações (OIM) sobre o conceito de migração², Celso Amorim Salim (1992) o define como:

Fenômeno de mobilidade espacial de determinada população entre unidades administrativas ou geográficas distintas,

\footnotetext{
${ }^{2}$ A OIM, associada à Organização das Nações Unidas (ONU), define em seu Glossário sobre migração que essa ideia exprime um "Processo de atravessamento de uma fronteira internacional ou de um Estado. É um movimento populacional que compreende qualquer deslocação de pessoas, independentemente da extensão, da composição ou das causas; inclui a migração de refugiados, pessoas deslocadas, pessoas desenraizadas e migrantes económicos" (OIM, 2009, p. 40).
} 


\section{Discussão sobre as diferentes abordagens teóricas para o estudo das migrações e da mobilidade do trabalho}

resultando em mudança de residência dos indivíduos e incluindo as variáveis distância percorrida e tempo de permanência, qualquer que seja a magnitude do fluxo que se deslocou (SALIM, 1992, p. 120-121).

Segundo o Dicionário crítico de migrações internacionais (2017, p. 453), o termo migração designa uma "mudança permanente de residência entre locais distantes”. Para que tal deslocamento seja considerado migração, ele deve seguir critérios temporais (quanto tempo o indivíduo permanece no local) e espaciais (uma distância mínima entre os locais de origem e destino). Tais critérios excluem da definição migração as mobilidades espaciais concernentes às viagens (turismo, negócios e de estudo), movimentos pendulares ou sazonais. Ainda que de difícil delimitação, esses parâmetros levam em conta sobretudo uma permanência, daquele que migra, de pelo menos alguns meses (tempo) e em uma unidade administrativa diferente da de origem, como um município, estado ou país (espaço).

O mesmo trabalho (idem, p. 461) define a migração forçada como subcategoria da migração internacional (entre países diferentes), e inclui movimentos de refugiados, deslocados internos e solicitantes de refúgio e sofre influência de relações políticas e geográficas de poder. Ambas as definições promovidas pelo dicionário, contudo, não são totalmente precisas uma vez que os movimentos migratórios abarcam uma série de dinâmicas complexas e contraditórias que dificultam a elaboração de generalizações.

Nesse sentido, faz-se necessário pontuar que Salim (1992) destaca a inexistência de uma unanimidade entre os critérios para classificar as diferentes correntes teóricas dos estudos sobre migração, sendo difícil de estabelecer uma linha cronológica de desenvolvimento das teorias sobre esse fenômeno. O que se vê nesse tema é uma série de antagonismos que dificulta a busca por uma unidade conceitual. $\mathrm{O}$ único aspecto comum a todas as abordagens, conforme o mesmo autor, é o fato de os movimentos migratórios terem como principal indutor um desequilíbrio espacial de origem econômica que produz diferenças na renda e no emprego entre os espaços de origem e destino.

Carmem Lussi (2015) salienta que o papel das teorias das migrações consiste na tarefa de compreender as forças fundamentais que conduzem os processos migratórios, e aprofundar o conhecimento a respeito deles é 
fundamental. Alejandro Portes (1997) defende que seja feita a construção de uma teoria das migrações que relacione articuladamente as diferentes abordagens desses fenômenos em cada área do conhecimento que os estuda. Douglas Massey et al. (2005) também seguem nesse sentido de formular uma explicação teórica sobre as migrações internacionais3.

Uma vez que os fenômenos migratórios abarcam uma série de elementos e problemáticas, em alguns casos particulares a determinado país, Lussi (2015) destaca que nenhuma teoria explica toda a realidade da mobilidade humana. Dessa forma, uma teoria sobre as migrações nunca esgota o conteúdo do fenômeno, sendo sempre necessário que tal teoria se transforme e evolua para abarcar os novos elementos que surgem na realidade estudada4.

Como continua a autora supracitada, as principais abordagens teóricas das migrações levam em conta sobretudo os aspectos de ordem econômica para explicar a mobilidade humana, com grande foco na migração do trabalho, que engloba a maior parte dos movimentos migratórios. No entanto, observa-se que no atual período vêm sendo desenvolvidos vários estudos que abarcam os movimentos migratórios decorrentes de guerras, desastres naturais e outros aspectos além dos econômicos (SOARES, 2014).

Salim (1992) identifica uma falta de unanimidade de uma classificação entre as diferentes correntes teóricas, evidenciando, em seu trabalho, vários exemplos de diferentes autores que buscaram organizar as variadas correntes 5 .

\footnotetext{
3 Massey et al. (2005) buscam formular uma teoria com base em quatro elementos principais, que são "[...] o estudo das forças estruturais que promovem a emigração dos países em desenvolvimento; a caracterização das forças estruturais que atraem imigrantes aos países desenvolvidos; a consideração das motivações, das metas e das aspirações das pessoas que respondem a tais forças, transformando-se em migrantes internacionais; e, o estudo das estruturas sociais e econômicas que surgem para conectar áreas de saída e de destino da migração" (MASSEY et al, 2005 apud LUSSI, 2015, p. 57).

4 Por abranger uma série de aspectos multidisciplinares, já foi pretendida por alguns autores, como o demógrafo francês Hervé Domenach (1998), a criação de uma "Migratologia", que seria uma área do conhecimento destinada a analisar os diferentes aspectos dos movimentos migratórios. A criação dessa nova disciplina poderia desenvolver as duas dimensões analíticas das migrações: "espaço-tempo" e "fluxos-estoques". Dessa forma, superaria a tendência dos estudos migratórios de seguirem um caminho baseado apenas nos dados e também se pautaria numa análise em que os conceitos emergiriam da realidade estudada.

5 Modelos neoclássicos contemporâneos e mobilidade da força de trabalho (Gaudemar, 1977); análises empiristas e escola histórico-estrutural (Gonzalez, 1979); análises sociológicas derivadas dos enfoques histórico-estruturalista e da modernização (Oliveira \& Stern, 1980); modelo de equilíbrio da migração e a perspectiva histórico-estrutural (Wood, 1982); as perspectivas demográfica, econômica, sociológica - incluindo a teoria da modernização - e histórico-estrutural (Raczynski, 1983); estudos quantitativistas, micro e macro-sociológicos (Aramburu, 1983); correntes psicologizantes face à concepção comportamental-racionalista e
} 


\section{Discussão sobre as diferentes abordagens teóricas para o estudo das migrações e da mobilidade do trabalho}

Vista essa grande diferenciação em cada autor estudado, Salim propõe elaborar três troncos teóricos para agregar e explicar as diferentes escolas que se integram nesses troncos:

- modelos neoclássicos contemporâneos, que se preocupam com a economia do espaço e a gestão capitalista da mão-deobra;

- perspectiva histórico-estrutural, vinculada à tradição dialética do marxismo e responsável por vasta produção crítica sobre a migração na América Latina;

- mobilidade da força de trabalho, cuja releitura dos economistas clássicos procura "reinventar" a análise da migração no processo geral de acumulação capitalista (SALIM, 1992, p. 122).

Por sua vez, segundo Hania Zlotnik (2003), são identificadas historicamente cinco principais teorias econômicas em que se basearam os estudos migratórios, sendo que as três primeiras desse grupo tem como fundamento a economia clássica, sobretudo a elaborada por Adam Smith. Tais correntes são a Teoria neoclássica, a Teoria da nova economia das migrações, a Teoria da migração familiar e da seletividade da migração (essas três pertencentes às concepções de origem neoclássica), a Teoria do duplo mercado de trabalho (ou mercado segmentado), e a Teoria do Sistema-mundo (World Systems Theory).

Tais concepções serão estudadas nas próximas seções, divididas entre aquelas influenciadas pelo pensamento econômico liberal (clássicas e neoclássicas) e aquelas desenvolvidas a partir do pensamento marxista (perspectiva histórico-estrutural e mobilidade da força de trabalho).

\section{CONCEPÇÕES CLÁSSICAS E NEOCLÁSSICAS}

As primeiras contribuições para o estudo das migrações se dão no período histórico de desenvolvimento do capitalismo comercial, entre os séculos XVI e XVIII e elaboradas por pensadores mercantilistas, se fortalecendo a partir da emergência, no século XVIII, das grandes migrações transoceânicas em decorrência do desenvolvimento dos meios de transporte, em um período de crescimento industrial do modo de produção capitalista. Segundo Gaudemar 
(1977), nesse período diversos autores discutem as diferentes visões a respeito do trabalho e de sua produtividade para a economia. Os principais precursores dessas discussões são Richard Cantillon, os economistas fisiocratas (como François Quesnay) e também Adam Smith (em seu A Riqueza das Nações), que colocam destaque no trabalho como formador de riquezas. Ainda não se há nesse momento um desenvolvimento da noção espacial enquanto abstração, mas a relação entre a natureza e o homem, que se apropria da terra para produzir riquezas, é o fator central. O trabalho nesse sentido é estudado sempre nas suas formas concretas.

No entanto, nesse período já se estudam as estruturas do trabalho, como a repartição espacial da população e as formas de mobilidade social, trazendo uma premissa de um possível surgimento do conceito de mobilidade do trabalho (GAUDEMAR, 1977). Além disso, o próprio conceito de mobilidade, como aponta o autor, só passa a ser utilizado para explicar os movimentos migratórios a partir do fim da Segunda Guerra Mundial, embora muitos estudos sobre as formas concretas de tal mobilidade já existissem (migrações). Após a segunda guerra os economistas começaram a analisar tal área tomando o caminho que havia sido aberto pela demografia no fim do Século XIX.

As concepções clássicas a respeito dos movimentos migratórios estão diretamente relacionadas às teorias econômicas de autores da economia clássica. Entre os principais teóricos desse período, deve-se destacar Adam Smith, David Ricardo, Jean-Baptiste Say e Thomas Malthus.

Adam Smith é o principal autor que conduz, com seu A Riqueza das Nações (1776), ao desenvolvimento da teoria econômica clássica, e também possui uma importância fundamental, na concepção de Gaudemar (1977), para o desenvolvimento dos troncos teóricos que passarão a estudar a mobilidade do trabalho.

Influenciado por autores como Cantillon (1755), Smith traz para o debate a relação não mais apenas entre o homem e a natureza (como era trabalhada pelas formulações anteriores), mas também a relação entre os homens (social). A noção do autor sobre a mobilidade é que ela é uma propriedade do trabalho que o torna capaz de ser produtivo e satisfazer as necessidades de desenvolvimento e acumulação do capital, tanto na qualificação do trabalho como na repartição social e setorial dos trabalhadores, determinando várias 


\section{Discussão sobre as diferentes abordagens teóricas para o estudo das migrações e da mobilidade do trabalho}

formas de mobilidade (GAUDEMAR, 1977; VAINER, 1998). Portanto, a mobilidade, na visão de Adam Smith, é a expressão de liberdade do homem, é uma mobilidade perfeita, que promove o desenvolvimento da economia e da riqueza (GAUDEMAR, 1977).

Adam Smith apresenta em seu estudo a primeira aproximação conceitual da mobilidade do trabalho, através de uma reflexão não apenas sobre o trabalho, mas sobre o espaço onde o trabalho se exerce. É também Smith o primeiro autor a esboçar uma possível problemática a ser tratada pelo conceito de mobilidade do trabalho. Dessa forma, é ele quem promove o desenvolvimento de tal conceito que, com a consolidação do capitalismo, assume novas formas e sua interpretação se divide em dois ramos distintos, que Gaudemar propõe-se a analisar: A teoria neoclássica e a marxista da mobilidade do trabalho.

Com o século XIX e o desenvolvimento do capitalismo industrial, uma série de autores liberais (clássicos) trazem suas ideias. Embora a mobilidade não seja, em seus trabalhos, explicitamente teorizada, sua noção está presente nas obras de tais autores, como Malthus, Ricardo e Say, dentro das reflexões a respeito do trabalho como também no destaque de algumas formas concretas de mobilidade (GAUDEMAR, 1977).

Embora tenham divergências em alguns aspectos, Ricardo e Say concordam na ideia de que a mobilidade do trabalho é essencial em se tratando das diferentes formas que o trabalho se sujeita às necessidades do capital, tanto na transformação em suas funções como nos locais em que se exerce. A visão de Say a respeito da mobilidade do trabalho é que ela está presente, como um meio, nas medidas das políticas econômicas destinadas a assegurar um equilíbrio econômico e social. Defendendo tal hipótese de mobilidade perfeita, o autor no entanto não aprofunda uma teorização sobre ela.

Já David Ricardo traz em sua análise uma justificativa para a mobilidade perfeita do trabalho, baseada na ideia de que o trabalho se configura como uma mercadoria. A mobilidade perfeita do trabalho exprime, então, a necessidade de o trabalho possuir uma característica para ser uma mercadoria. É aqui que Gaudemar (1977) pontua que Ricardo busca uma axiomatização da mobilidade do trabalho (que mais tarde será promovida pelos neoclássicos). 
Malthus, por sua vez, se afasta dessa perspectiva de "axiomatização da mobilidade" (que a configuraria como mobilidade perfeita), trazendo uma concepção mais concreta do modo de funcionamento do capitalismo em que não é possível que o mercado se autorregule (como defendem os outros teóricos clássicos como Say e Ricardo). O pensamento de Malthus, nesse sentido, se afasta do defendido por Ricardo e Say, e se aproxima da teorização de Jean de Sismondi.

Sismondi, conforme Gaudemar (1977) analisa, é o único autor prémarxista que rompe com a ideia predominante de uma mobilidade do trabalho que deve ser incentivada e colocada a serviço da acumulação do capital. Trazendo uma crítica ao capitalismo e sua atuação a partir da mobilidade do trabalho, Sismondi introduz em sua análise com mais intensidade a noção de espaço, bastante ocultado concretamente pelos autores clássicos, e, por isso mesmo, ignoradas por eles as contradições presentes em tais espaços. Mesmo sem grande aprofundamento teórico, o autor, com sua ruptura, abre caminho para Marx desenvolver sua teoria de tal modo de produção (GAUDEMAR, 1977).

Com Marx e os marxistas, a mobilidade do trabalho passa a ser estudada sobretudo em seu aspecto estrutural. Em resposta e como crítica a visão marxista, surgem também os pensadores neoclássicos, que defendem a mobilidade do trabalho com base nas ideias dos autores clássicos, especialmente Ricardo e Say, axiomatizando a teoria de equilíbrio geral dos autores. De maneira geral, Gaudemar (1977) traz um resumo do processo histórico de desenvolvimento do conceito de mobilidade do trabalho e como a contribuição de Adam Smith foi essencial para a formação de dois ramos diferenciados de análise desse processo filiados à escolas econômicas diferentes:

O tronco conduz ao longo do século XVIII, através da complexidade do período de transição para o capitalismo, de Cantillon a Smith passando pelos fisiocratas. Smith constitui a bifurcação a partir da qual se efectua a separação em dois ramos distintos, um que se dirige para Sismondi, depois para Marx e os marxistas, o outro para os clássicos, Walras e os neoclássicos, atravessando cada um destes dois ramos, de modo diferente, a mesma cronologia, porque colocando-se diferentemente face ao desenvolvimento capitalista (GAUDEMAR, 1977, p. 100). 


\section{Discussão sobre as diferentes abordagens teóricas para o estudo das migrações e da mobilidade do trabalho}

Com base nessa abordagem de Gaudemar, pode-se dividir o desenvolvimento do conceito de mobilidade do trabalho em três fases diferentes, como elencado na figura 1.

Figura 1: Desenvolvimento do conceito de mobilidade do trabalho.

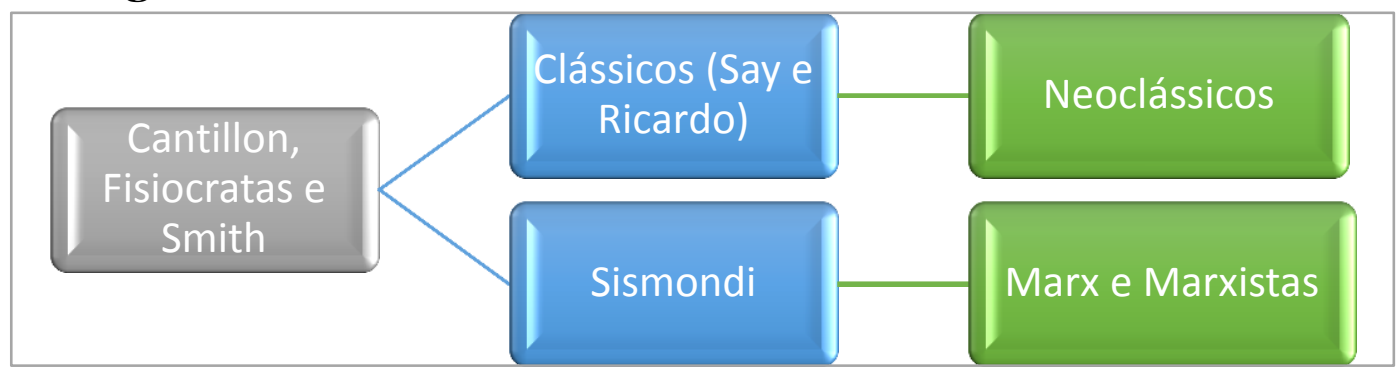

Fonte: GAUDEMAR (1977).

Gaudemar, deste modo, realiza uma análise dos dois troncos que tratam, já no período de domínio capitalista, sobre a mobilidade do trabalho: De um lado, os autores neoclássicos, como Walras, que axiomatizam tal ideia com base na contribuição dos autores clássicos e na escola do liberalismo econômico; e de outro lado, Marx e os marxistas, que aprofundam sua análise no aspecto estrutural da mobilidade do trabalho, enquanto aspecto central do modo de produção capitalista e de sua reprodução ampliada.

Segundo Lussi (2015), a teoria neoclássica tem como base fundamental a teoria econômica clássica de Adam Smith, e defende que os movimentos migratórios ocorrem em decorrência da decisão dos próprios trabalhadores, que são agentes livres que escolhem migrar com base em cálculos de custobenefício, se transferindo para lugares onde podem obter melhor salário. Dessa forma, a visão dos neoclássicos, como destacam Leite, Giavarotti, Kluck et al (2017, p. 9) pensa "os movimentos populacionais como mobilidade geográfica dos trabalhadores em um espaço econômico isomórfico, motivados nomeadamente pelos desequilíbrios existentes na oferta de emprego e renda".

Oliveira (2006) salienta que os neoclássicos defendem que os deslocamentos humanos estão inseridos numa lógica de oposição entre pobreza e oportunidades: enquanto uma região pobre e rural seria um fator de expulsão das pessoas, as oportunidades dos centros urbanos, dotados de maiores possibilidades de obtenção de renda, lazer, educação etc. dariam a esses lugares uma atração para os deslocamentos, sendo que o desenvolvimento tecnológico 
agiria como um atenuante para tais fluxos. Dessa forma, esse raciocínio se baseia especialmente no diferencial de renda dos diferentes espaços, que influenciaria o movimento migratório. $\mathrm{O}$ indivíduo então, que segundo essa interpretação pode mover-se livremente pelo território, irá se deslocar para um local onde haja maior vantagem para a venda de sua mão-de-obra (OLIVEIRA, 2006).

Nesse sentido é que Gaudemar (1977) afirma que para os neoclássicos, em especial Stanley R. Dennison, a migração é o mecanismo que promove o equilíbrio entre oferta e procura:

O postulado de mobilidade perfeita do trabalho funda assim a
tese que diz: quando os homens se sentem bem onde estão, seja
em que sítio for, nenhuma migração modifica este estado
máximo da sua satisfação, desde que os rendimentos se
mantenham inalteráveis. Consequentemente, as formas
espaciais da mobilidade do trabalho não são mais do que
mecanismos que permitem ao indivíduo aceder ou manter-se
em locais em que sua satisfação, reduzida à sua transparência
monetária, é máxima, não sendo a mobilidade do trabalho mais
do que o postulado de comportamento de um fator de produção,
tornando possível a existência destes mecanismos
(GAUDEMAR, 1977, p. 145).

A perspectiva neoclássica - ou enfoque, como define Becker (1997), tem como principal pioneiro Léon Walras, que buscou realizar a axiomatização do conceito de trabalho e de sua mobilidade a partir das teorias de autores da economia clássica, principalmente as de David Ricardo. Walras considera que a partir da axiomatização é possível considerar a mobilidade do trabalho uma mobilidade perfeita, uma vez que os movimentos migratórios tenderiam a equilibrar as ofertas de salário e emprego nos países de origem e de destino dos migrantes. O autor, dessa forma, abre o caminho para interpretações dos movimentos migratórios com base na teoria econômica burguesa e utilizando-se de processos matemáticos para definir seus componentes.

Ernst Georg Ravenstein é outro pensador a se destacar, autor de As leis da migração, de 1885, primeiro trabalho acadêmico reconhecidamente sobre teoria das migrações, conforme Lussi (2015) argumenta. Nesse artigo, o autor estuda as migrações internas na Grã-Bretanha do século XIX com base no empirismo e em dados do Censo inglês de 1881. A partir de uma série de leis sobre o fenômeno, Ravenstein teve grande destaque durante esse período. Além 


\section{Discussão sobre as diferentes abordagens teóricas para o estudo das migrações e da mobilidade do trabalho}

disso, é contemporâneo de Walras e considerado pertencente à escola neoclássica (BECKER, 1997; OLIVEIRA, 2006), ainda que autores como Pereira Neto (2019) discordem de tal acepção.

Após Ravenstein, destacou-se a teoria migratória da Escola de Chicago, que predominou nos estudos sobre migrações por quase um século e trouxe uma metodologia para seu estudo. Tal teoria (que se originou no estudo das migrações internas norte-americanas) teve grande destaque nas décadas de 1920 e 1930 e predominou até a década de 1960 (LUSSI, 2015). Larry Sjaastad e Theodore Schultz se inserem como representantes dessa escola de pensamento.

Michael P. Todaro, um dos autores da teoria neoclássica, trabalha sobretudo com a mobilidade campo-cidade, em que o crescimento industrial nas cidades (modernização) move o processo migratório do campo para a cidade. Como bem trazido por Pereira Neto (2019), Todaro elabora em seu artigo $A$ migração da mão-de-obra e o desemprego urbano em países subdesenvolvidos, de 1969, um modelo para explicar as migrações ruralurbanas. Ele considera que o trabalhador migrante decide se deslocar em função do diferencial de renda real que existe entre o rural e o urbano e da probabilidade de conseguir um emprego urbano (TODARO, 1980 apud PEREIRA NETO, 2019). Embora traga essa ideia do diferencial de renda, Pereira Neto (2019) não considera Todaro propriamente um autor da corrente neoclássica, ainda que autores como Salim (1992) e Oliveira (2011) discordem de tal afirmação.

Além desses, vários outros autores contribuíram para o debate dentro da teoria neoclássica da migração, como Alfred Weber, Weigmann, August Lösch, e o já referido Stanley R. Dennison, entre outros. Nessa perspectiva, Pereira Neto (2019) afirma sobre a visão neoclássica:

Como idealizado pela teoria neoclássica, num mundo de concorrência perfeita, o livre jogo do mercado, sem interferência do Estado, seria responsável por alocar eficientemente os fatores de produção, inclusive o fator trabalho. Portanto, o trabalhador somente ficaria desempregado se não aceitasse o nível de salário vigente no mercado (PEREIRA NETO, 2019, p. 492).

Vários autores já estabeleceram críticas a essa teoria (GAUDEMAR, 1977; SALIM，1992; BECKER，1997; OLIVEIRA，2006; LUSSI，2015; PEREIRA 
NETO, 2019), que no geral apontam o fato de existir uma ligação entre a teoria neoclássica das migrações com as teorias demográficas clássicas, que priorizam a relação entre os fatores de expulsão do país de origem e os fatores de atração do país de destino (push-pull theory). Segundo Lussi (2015), as críticas detalham que tal abordagem foi desenvolvida para explicar os movimentos migratórios durante a era industrial, e por isso não podem ser utilizadas para explicar a complexa dinâmica do atual período histórico do capitalismo.

É também bastante limitada tal teoria neoclássica, segundo Zlotnik (2003), pois não consegue incorporar em seu discurso os contextos políticos e econômicos internacionais e também nacionais, que influenciam as decisões de migrar ou não. A crítica ao fato de ser levada em conta fundamentalmente a visão individual na decisão de migrar é também essencial. Nesse sentido é que Gaudemar (1977) afirma ser a teoria neoclássica das migrações fundamentalmente uma teoria elaborada para os interesses do capital e de sua acumulação.

Algumas releituras da teoria neoclássica foram elaboradas na segunda metade do século XX, em especial entre as décadas de 1960 e 1970, que buscaram abarcar um número maior de possibilidades para os movimentos populacionais. Lussi (2015) realiza um apanhado de tais concepções, destacando, entre elas, a teoria da nova economia das migrações; teoria da migração familiar e da seletividade da migração; e a teoria do duplo mercado de trabalho (ou mercado segmentado), esta última já incorpora alguns pressupostos estruturais que são desenvolvidos na abordagem históricoestrutural.

A crítica de Lussi e de Zlotnik às abordagens acima detalhadas se baseia no fato de elas serem fundamentalmente econômicas, e por isso priorizam um aspecto e não o articulam suficientemente a contextos mais complexos da realidade, não sendo considerados nelas os complexos aspectos que existem nas esferas política e econômica que se destacam no atual período do capitalismo, como as políticas empenhadas pelos Estados nacionais, evidenciadas no controle de fronteiras e criminalização da migração (LUSSI, 2015). Em vista disso, se faz mister a elaboração de uma teoria das migrações que agregue em seu complexo fatores econômicos, políticos, sociais, culturais, psicológicos e mesmo ambientais. 


\section{Discussão sobre as diferentes abordagens teóricas para o estudo das migrações e da mobilidade do trabalho}

É com base nessa necessidade de incorporar um leque maior de fatores nas análises migratórias é que se desenvolvem, a partir das décadas de 1970 e 1980, trabalhos que se apoiam principalmente na visão marxista do modo de produção capitalista. Lussi (2015) foca sua análise em uma delas, a chamada World Systems Theory. No entanto, várias outras se incorporam às teorias histórico-estruturais e da mobilidade do trabalho.

\section{A ABORDAGEM HISTÓRICO-ESTRUTURAL}

A abordagem histórico-estrutural busca fazer oposição à análise neoclássica ao não mais considerar apenas as decisões individuais dos migrantes face a uma possibilidade de se mover com total liberdade, mas considera que os fatores estruturais (contextos históricos e geográficos específicos) são determinantes para a migração, já que pressionam os grupos e classes sociais e não garantem a eles liberdade de deslocamento. Deste modo, o indivíduo não possui liberdade para decidir sobre sua migração, pois está engendrado em uma conjuntura histórica e estrutural específica.

Segundo destaca Becker (1997), com a análise do caráter histórico, empenhada pela teoria histórico-estrutural para compreender a migração, a ideia de mobilidade espacial da população expande seu arcabouço analítico. Singer (1973) tem grande importância para trazer o fator histórico em conta, definindo a migração como "fenômeno social historicamente condicionado, tornando-se o resultado de processo global de mudanças, separado do qual não deveria ser analisado" (SINGER, 1973, p. 267).

Conforme Salim (1992), existe um grande número de estudos feitos dentro dessa abordagem, e por isso mesmo há uma dificuldade em sumarizar tais trabalhos sob apenas um enfoque, algo também destacado por Oliveira (2011). Alguns pontos em comum, contudo, são identificados por Salim: caracterização da migração a partir dos elementos estruturais presentes no espaço geográfico em que se apresenta; foco nas questões econômicas como majoritárias (relações de produção, modos de produção e mecanismos de exploração); análise de outros tipos de migração além da rural-urbana (como as migrações temporárias); definição de classes sociais com base nas relações de 
produção dominantes, levando em conta as desigualdades promovidas pelo capitalismo.

Paul Singer $(1973,1998)$ defende que as migrações internas são movidas pelas desigualdades regionais, uma vez que o desenvolvimento desigual e combinado das regiões faz com que os trabalhadores que vivem em áreas desfavorecidas se empobreçam na medida em que os excedentes são transferidos para as regiões economicamente mais ricas. Há para o autor dois tipos de fatores de expulsão da população nas áreas mais pobres: Os de mudança e os de estagnação. Os fatores de mudança estão associados à introdução das relações de produção capitalistas que retiram dos camponeses seus meios de trabalho e aumentam o nível de produtividade do trabalho; os fatores de estagnação dizem respeito à uma crescente pressão populacional sobre áreas de cultivo cada vez menos disponíveis (em decorrência da estrutura agrária e da qualidade inferior dos terrenos). Singer destaca, no entanto, que no primeiro fator haveria a possibilidade de um efeito positivo com o aumento da produtividade do trabalho para a população, desde que os atores políticos e sociais locais garantissem a repartição da renda excedente produzida.

Como continua Singer $(1973,1998)$, a piora nas condições de vida e de trabalho transformaria essas regiões empobrecidas em viveiros de mão-deobra, que são espaços em que a população sobrevive com base em uma economia de subsistência durante os períodos em que seu trabalho não é requisitado para cobrir a demanda por mão-de-obra, estando assim essas regiões disponíveis de acordo as necessidades do capital. Essa ideia de viveiros de mão-de-obra está associada ao conceito de superpopulação relativa, que é inerente ao modo de produção capitalista.

Para o autor, portanto, essas forças de expulsão vão definir as áreas onde se originam os fluxos migratórios, que irão se destinar a áreas que apresentem forças de atração, essas estão associadas a atração de força de trabalho com base na dinâmica do capital. Ainda como Singer (1998) destaca, em se tratando da migração interna, ainda que a afirmação a seguir também possa caber às migrações internacionais, o autor salienta que "Se se admite que a migração interna é um processo social, deve-se supor que ele tenha causas estruturais que impelem determinados grupos a se pôr em movimento" (SINGER, 1998, p. 52). 


\section{Discussão sobre as diferentes abordagens teóricas para o estudo das migrações e da mobilidade do trabalho}

O referido autor defende que tais causas estruturais são quase sempre de ordem econômica.

Além disso, sobre as causas e motivos das migrações, é necessário distinguir ambas, conforme Singer (1998): os motivos, que são de ordem individual, se manifestam dentro de um quadro geral de determinações socioeconômicas que induzem a migrar, que são as causas. Nessa lógica, as causas, que são de ordem social e econômica (de classe), se constituem como primeira determinação da migração, depois seguida pelos motivos (SINGER, 1998). Uma vez que a migração é um processo social, e por isso a unidade migratória não é um indivíduo, mas sim um grupo social, ela deve ser estudada para além de apenas um movimento de indivíduos em um dado período entre dois pontos ${ }^{6}$.

Como crítica ao enfoque histórico-estrutural, Vainer (1998) traz uma análise do processo histórico da acumulação primitiva do capital, em que tevese o uso de mecanismos de coerção por parte do Estado, como a violência que expropriou os camponeses e os enviou para a fábrica e para os bairros operários das cidades. Para a visão histórico-estrutural, segundo Vainer (1998) essa violência no entanto diminui à medida que o capitalismo se desenvolve. Dessa forma, os mecanismos de coerção e violência mostram-se essenciais no período pré-capitalista, mas não em seu desenvolvimento a partir do período industrial.

Assim, o autor destaca que tanto a abordagem neoclássica como a estrutural mostram-se incapazes de analisar o papel da coerção, da violência e das relações de poder na produção e reprodução dos deslocamentos no movimento de acumulação capitalista já no período de seu domínio. Dessa maneira, os deslocamentos compulsórios e as restrições à circulação correspondem a um território que não é nem espaço abstrato da racionalidade, nem apenas manifestação da estrutura, mas sim um lugar do conflito e do exercício do poder (VAINER, 1998). Antonio Tadeu Ribeiro de Oliveira (2011)

\footnotetext{
${ }^{6}$ Como ainda salienta Singer (1998, p.54) "quando uma classe social se põe em movimento, ela cria um fluxo migratório que pode ser de longa duração e que descreve um trajeto que pode englobar vários pontos de origem e de destino. É o fluxo migratório originado por determinados fatores estruturais, que determinam o seu desdobramento no espaço e no tempo, o primeiro objeto de estudo. Uma vez compreendidos o fluxo, as suas causas e os fatores condicionantes, determinados movimentos que o compõem podem ser investigados isoladamente. A hipótese básica, no entanto, é que o fluxo determina os movimentos unitários, e estes só podem ser compreendidos no quadro mais geral daquele".
} 
concorda com as afirmações de Vainer, e salienta a importância de se analisar o papel da coerção e das relações políticas entre os Estados nacionais para compreender as migrações.

Como também critica Salim (1992), tal abordagem vê a migração como reflexo do espaço transformado, e não como agente de transformação de tal espaço, justamente por isso se faz a diferenciação principal em relação à abordagem da mobilidade do trabalho. Os autores trabalhados acima concordam com a necessidade de um enfoque que seja diferente do neoclássico e do histórico-estruturalista, é esse o caminho que toma a teoria da mobilidade do trabalho, chamada por Becker (1997) de enfoque neomarxista.

\section{A ABORDAGEM MARXISTA DA MOBILIDADE DO TRABALHO}

A abordagem marxista da mobilidade do trabalho surge como crítica à ambos os postulados anteriores, baseando-se sobretudo na crítica marxista dos deslocamentos espaciais e fundamentada na teoria do trabalho de Marx. Vários autores analisados (SALIM, 1992; BECKER, 1997; BRUMES, 2003; KLUCK, 2011; SOARES, 2014; TELES, 2014) concordam que Gaudemar (1977) é um dos nomes mais importantes a formular tal abordagem, promovendo uma análise pautada na relação entre capital e trabalho, tanto na produção como na reprodução dessa relação. Nesse sentido, a mobilidade do trabalho é enxergada como central no processo de acumulação capitalista e no desenvolvimento das forças produtivas (TELES, 2014).

É através de Gaudemar (1977) que a análise da migração passa a considerá-la como uma crescente sujeição do trabalho ao capital. Passa-se a se falar em mobilidade forçada como resposta à ideia neoclássica de uma mobilidade livre e determinada apenas pelo próprio indivíduo.

Gaudemar objetiva em seu trabalho formular um conceito que possa designar o uso capitalista da mercadoria força de trabalho, que defina a qualidade da força de trabalho, que se não existisse, não haveria uso capitalista (que produz mais-valia). Com base no emprego de Marx sobre o termo, Gaudemar (1977) acredita que apenas o conceito de mobilidade parece dar conta das várias aptidões necessárias à força do trabalho para ela ser utilizada para a produção da mais-valia. Essa mobilidade, tanto no tempo como especificamente no espaço, é ao mesmo tempo determinada e determinante do 


\section{Discussão sobre as diferentes abordagens teóricas para o estudo das migrações e da mobilidade do trabalho}

processo de acumulação capitalista, e não pode ser totalmente compreendida senão nesse contexto (GAUDEMAR, 1977).

Deste modo, Gaudemar é quem atribui à mobilidade uma característica da força de trabalho, de extrema importância enquanto uma dimensão de análise para a crítica ao processo de reprodução ampliada do capital. A ideia principal, segundo Leite, Giavarotti, Kluck et al. (2017, p. 12), que o economista francês defende em sua obra é o estudo sobre:

Quais condições históricas produziram a possibilidade de que os capitalistas, de posse de recursos assim passíveis de serem transformados em capital, encontrassem no mercado uma mercadoria disponível cujo valor de uso consiste na virtude particular dela ser fonte de riqueza, enquanto seu valor de troca se reduz simplesmente aos custos de sua reprodução. E não apenas disponível para ser consumida, mas mobilizável em todas as suas dimensões de circulação e utilização, de modo a viabilizar o processo de acumulação capitalista.

Para fundamentar sua análise, Gaudemar (1977) destaca que a constituição do capitalismo dependeu do fato de o trabalho ganhar a qualidade de ser móvel, o que possibilitou a transformação do trabalho em mercadoria: a força de trabalho. Assim, o trabalho se transforma, com o capitalismo, em força de trabalho, possuindo como uma de suas qualidades a capacidade de ser móvel, espacialmente ou socialmente. Sendo uma mercadoria, essa força de trabalho possui um valor, que é medido pelo tempo de trabalho necessário à sua produção. Assim sendo, existe um processo de produção da força de trabalho.

Como continua o autor supracitado, para que o dinheiro se torne capital, é necessário que exista no mercado um trabalhador livre, em dois sentidos: primeiramente por possuir a força de trabalho como uma mercadoria sua; ao mesmo tempo precisa não ter qualquer outra mercadoria que possa vender, não possuindo qualquer instrumento necessário para a realização de sua força de trabalho. Tais liberdades são, na ótica de Gaudemar, uma dupla determinação: uma liberdade positiva e uma negativa, respectivamente. Ao mesmo tempo que o homem é livre para possuir sua própria força de trabalho, ele é obrigado a vendê-la para poder viver, pois se não vende sua força de trabalho, ele morre.

É esta liberdade dupla que define, conforme o autor, o caráter móvel da força de trabalho. Significa dizer que o trabalhador, mesmo aparentemente 
podendo escolher seu trabalho e onde o realizar, ele está sempre submetido às exigências da valorização do valor?.

Além disso, o autor ainda sublinha que a mobilidade de trabalho, em suas várias formas de manifestação (como a espacial, correspondente à migração) é um dispositivo central para o processo de acumulação capitalista:

$\mathrm{Na}$ sua dimensão espacial, ela assegura a repartição dos indivíduos no espaço, na sua dimensão profissional, constitui o postulado implícito de toda a nomenclatura dita homogénia, portanto de toda a codificação das actividades; na sua dimensão produtiva mais geral, ela conduz a todos os processos pelos quais o capital dispõe das forças de trabalho e as usa na multiplicidade dos processos de extorsão da mais-valia tanto absoluta como relativa (GAUDEMAR, 1977, p. 51).

Visto isso, a abordagem pela qual o economista estuda a mobilidade se baseia sobretudo nas concepções de Marx sobre a mais-valia e também sobre os valores de uso e de troca.

Para Becker (1997), no capitalismo a mobilidade configura-se como um meio para a reprodução do capital, já que ele necessita de uma mão-de-obra livre e móvel para produzir o excedente de capital. Sendo assim, a migração se coloca como um mecanismo na produção de força de trabalho ao atrelar "áreas de diferentes escalas espaciais (regional, nacional, internacional) objetivando a expansão do mercado de trabalho" (BECKER, 1997, p. 342).

A autora supracitada também explica a diferença essencial na categoria de análise dos estudos da mobilidade entre os enfoques neoclássicos e neomarxistas (entendidos por ela como referentes à abordagem marxista da mobilidade do trabalho). Enquanto os neoclássicos partem de uma análise dos indivíduos propriamente ditos, a visão neomarxista estuda as classes sociais, ou determinados grupos sócio-econômicos. Outras diferenças entre as duas abordagens são abordadas pela autora em um quadro (Figura 2).

\footnotetext{
7 Concernente a tal aspecto, Heidemann (2010, p. 15) retoma os destaques de Gaudemar (1977), e complementa que "ser móvel significa, portanto, estar apto para os deslocamentos e modificações no emprego, na realização de trabalho abstrato, como também ser indiferente ao conteúdo do trabalho, tanto quanto o capital o é, desde que tenha êxito no processo de valorização do valor".
} 


\section{Discussão sobre as diferentes abordagens teóricas para o estudo das migrações e da mobilidade do trabalho}

Figura 2: Diferenças entre os enfoques neoclássico e neomarxista no estudo das migrações.

\begin{tabular}{|c|c|}
\hline Enfoque neoclássico & Enfoque neomarxista \\
\hline $\begin{array}{l}\text { Decisão de migrar: } \\
\text { - Ato de caráter individual, de livre escolha e } \\
\text { não determinado por fatores externos; } \\
\text { - Pretensamente neutro e apolítico. }\end{array}$ & $\begin{array}{l}\text { Decisão de migrar: } \\
\text { - Migração como mobilidade forçada pela } \\
\text { necessidade de valorização do capital. }\end{array}$ \\
\hline $\begin{array}{l}\text { Significado: } \\
\text { - Elemento de equilíbrio nas economias } \\
\text { subdesenvolvidas; } \\
\text { - Industrialização e modernização são forças } \\
\text { positivas que alavancam a migração. }\end{array}$ & $\begin{array}{l}\quad \text { Significado: } \\
\text { - Resultado de um processo global de } \\
\text { mudanças; } \\
\text { - Expressão da crescente sujeição do trabalho } \\
\text { ao capital. }\end{array}$ \\
\hline $\begin{array}{l}\text { Metodologia: } \\
\text { - Análise descritiva, dualista e setorial do } \\
\text { fenômeno; } \\
\text { - Enfoque causal, isolado e pontual das } \\
\text { migrações; } \\
\text { - Características individuais predominam. }\end{array}$ & $\begin{array}{l}\text { Metodologia: } \\
\text { - Análise histórico-estrutural dos processos; } \\
\text { - Enfoque dialético; } \\
\text { - Predominam os grupos sociais na análise }\end{array}$ \\
\hline $\begin{array}{l}\text { Categoria de análise: } \\
\text { - Indivíduo. }\end{array}$ & $\begin{array}{l}\text { Categoria de análise: } \\
\text { - Grupos sociais. }\end{array}$ \\
\hline $\begin{array}{l}\text { Dimensão espaço-temporal: } \\
\text { - Deslocamento entre dois pontos no espaço } \\
\text { (fluxos, linhas); } \\
\text { - Mercado de trabalho homogêneo e pontual. }\end{array}$ & $\begin{array}{l}\quad \text { Dimensão espaço-temporal: } \\
\text { - Movimento de um grupo em um certo } \\
\text { período do tempo e sobre o espaço } \\
\text { geográfico, é um processo que pode ser em } \\
\text { vários pontos e com duração variada; } \\
\text { - Mercado de trabalho multidimensional e } \\
\text { em transformação no tempo e espaço. }\end{array}$ \\
\hline
\end{tabular}

Fonte: Adaptado de BECKER (1997).

Como pode ser observado no quadro elaborado por Becker, muitas diferenças são notadas entre os dois enfoques tratados por ela. É nesse sentido que um estudo que se baseie nas categorias e conceitos do pensamento marxista para explicar os fenômenos migratórios deve analisá-los com base nas relações conflitantes que se dão entre o trabalho e o capital dentro do modo de produção capitalista.

Embora o quadro elaborado por Becker (1997) mostre as diferenças nas principais características dos enfoques neoclássico e neomarxista (mobilidade do trabalho), novos aspectos são introduzidos aos estudos das migrações no período contemporâneo do capitalismo e sobretudo neste início de século XXI. Dessa maneira, consideramos necessário discutir esses novos elementos que se fazem presentes nas dinâmicas migratórias atuais. 


\section{ABORDAGENS RECENTES NO ESTUDO DAS MIGRAÇÕES}

Os estudos dos movimentos migratórios recentes têm incorporado uma série de novos aspectos na busca para interpretar as várias complexidades características aos processos migratórios do presente. Uma série de autores estudam as dinâmicas migratórias e os diferentes processos de mobilidade da população, que trazem uma série de desafios teóricos e conceituais para compreender as migrações, como destaca Baeninger (2012). Essa autora, bem como outros pesquisadores do mundo todo como Canales (2015) e diversas instituições (NEPO-UNICAMP, OIM, ACNUR, NIEM-RJ entre outros) têm trazido uma série de contribuições para o estudo dos movimentos migratórios que se dão nas últimas décadas. Esses esforços têm sido refletidos na elaboração de livros e coletâneas, que incorporam os trabalhos de diversos pesquisadores dos processos migratórios a respeito tanto no caso do Brasil - como em São Paulo (BAENINGER, 2012), como entre países do Hemisfério Sul (BAENINGER et al., 2018), e entre Bolívia (BAENINGER, 2012), Haiti (BAENINGER et al., 2016) e Venezuela (BAENINGER et al., 2018) e o Brasil.

Além disso, uma diversidade de temas e esferas tem caracterizado o estudo das migrações na atualidade, que também incluem análises de múltiplas disciplinas e áreas do conhecimento (Geografia, demografia, economia, antropologia, ciência política, história entre outros). Podem se destacar temas referentes a questão do refúgio (CALEGARI \& JUSTINO, 2016; CALEGARI, 2018) das fronteiras e dinâmicas territoriais (PÓVOA NETO, 2005; HAESBAERT, 2012; DUPAS, BOTELHO \& ROMERO, 2017; BAENINGER \& CANALES, 2018), das relações de poder (VAINER, 1998); da questão das identidades (SEYFERTH, 2005; SASAKI, 2005, BAINES, 2012), discussões sobre gênero (KITAHARA, 2005; RODRIGUES \& VASCONCELOS, 2012) políticas migratórias (REIS, 2007; MOULIN, 2012) entre outros.

Para interpretar os movimentos migratórios que se dão no período recente do capitalismo, com base em um enfoque marxista da mobilidade do trabalho, deve-se levar em conta as novas determinações do capitalismo em sua fase de crise estrutural, que tem se mostrado mais intensa a partir de fins do século XX. Vários autores marxistas contemporâneos (IANNI, 2001; HARVEY, 2013; ANTUNES, 2015) identificam que o período de hegemonia do neoliberalismo como modelo econômico, a partir da década de 1970, trouxe 


\section{Discussão sobre as diferentes abordagens teóricas para o estudo das migrações e da mobilidade do trabalho}

profundos impactos para o mundo do trabalho, que sofre uma série de mudanças e retrocessos que podem ser vistos na flexibilização do trabalho e em outros mecanismos para garantir maior exploração do trabalho e aumento da acumulação de mais-valia.

Ainda no escopo marxista, Valencia (2009) traz o papel das relações entre diferentes estados nacionais sob a lógica do imperialismo. As migrações, nesse sentido, têm relevado destaque para se compreender as dinâmicas de acumulação de capital que se realizam no atual período de reprodução ampliada do capital, e que revelam as relações imperialistas entre Estados do centro e da periferia do capitalismo. O papel do Estado também segue essa lógica, atuando no sentido de promover movimentações da força de trabalho que garantam maior valorização do capital (GAUDEMAR, 1977; MASCARO, 2013).

Dentro da geografia, vários autores estudam a mobilidade espacial do trabalho através das migrações, entre eles podemos destacar Perpetua e Thomaz Junior (2004), Silva (2008), Kluck (2011), Teles (2014), Soares (2014) entre outros. Um autor central nessa análise é David Harvey, que em vários trabalhos (2004, 2005, 2013) promove o debate sobre o imperialismo como elemento fundamental para compreender as novas determinações que influenciam os processos migratórios, estabelecendo uma discussão que também inclui o papel da crise estrutural do capital como agente fundamental para a mobilidade do trabalho e do capital.

\section{CONSIDERAÇÕES FINAIS}

De maneira geral, podemos evidenciar, a partir do que fora discutido anteriormente, que o desenvolvimento das principais abordagens sobre as migrações têm forte relação com a evolução do pensamento econômico. Também podemos afirmar que os movimentos migratórios têm se complexificado na medida em que o capitalismo apresenta novas características em seu movimento de acumulação expandida. Autores como Becker (1997) e Lussi (2015) destacam a importância de se estudar os fenômenos migratórios, especialmente na realidade atual do modo de produção capitalista, que desde 
meados da década de 1970 passa por um período de crise de acumulação que evidencia uma crise estrutural desse modo de produção.

Já no século XXI, percebemos uma grande variedade de temas sendo tratados por parte dos estudos migratórios, que agora englobam não só aspectos econômicos e políticos, mas também de refúgio, socioambientais, de gênero, geopolíticos entre outros. A multidisciplinaridade tem sido presente nos estudos migratórios do presente.

Desta forma, tais discussões se mostram essenciais para compreender, na atualidade, como os diferentes processos migratórios são condicionados e quais as determinações do atual período histórico do capitalismo são centrais para se compreender tais processos, bem como para buscar um entendimento sobre como esses elementos influenciam na produção e reprodução dos espaços impactados por tais determinações.

\section{REFERÊNCIAS}

ANTUNES, R. Adeus ao trabalho?: Ensaios sobre as metamorfoses e a centralidade do mundo do trabalho. 16. Ed. São Paulo: Cortez, 2015.

BAENINGER, R. Fases e faces da migração em São Paulo. Campinas: Núcleo de Estudos de População-Nepo/Unicamp, 2012.

BAENINGER, R. (Org.). Imigração Boliviana no Brasil. Campinas: Núcleo de Estudos de População-Nepo/Unicamp; Fapesp; CNPq; Unfpa, 2012.

BAENINGER, R. et al. Migrações Sul-Sul. Campinas: Núcleo de Estudos de População-Nepo/Unicamp, 2018 ( $2^{\circ}$ edição).

BAENINGER, R. et al. (Org.). Imigração Haitiana no Brasil. Jundiaí: Paco Editorial, 2016.

BAENINGER, R.; CANALES, A. (Coord.). Migrações Fronteiriças. Campinas: Núcleo de Estudos de População-Nepo/Unicamp, 2018.

BAENINGER, R.; SILVA, J. C. J. (Coord.). Migrações Venezuelanas. Campinas: Núcleo de Estudos de População-Nepo/Unicamp, 2018.

BECKER, O. M. S. Mobilidade espacial da população: Conceitos, tipologias, contextos. In: CASTRO, I. E.; GOMES, P. C. C.; CORRÊA, R. L. Explorações Geográficas: Percursos no fim do século. Rio de Janeiro: Bertrand Brasil. 1997.

BRUMES, K. R. Movimentos migratórios em cidades médias: o caso de Uberlândia-MG (1970-2000). Dissertação (Mestrado). Universidade Estadual Paulista. Presidente Prudente, 2003.

CALEGARI, M. PANORAMA DO REFÚGIO NO SÉCULO XXI: OS REFUGIADOS SÍRIOS NO BRASIL E NO MUNDO. In: XXI Encontro Nacional de Estudos Populacionais, ABEP, 2018. 
CALEGARI, M.; JUSTINO, L. REFUGIADOS SÍRIOS EM SÃO PAULO: O DIREITO À INTEGRAÇÃO. In: Seminário "Migrações Internacionais, Refúgio e Políticas”, a ser realizado no dia 12 de abril de 2016 no Memorial da América Latina, São Paulo.

CANALES, A. E pur si muove - Elementos para una teoria de las migraciones en el capitalismo global. Guadalajara, México: Universidad de Guadalajara, MAPorruá Editor, 2015.

CAVALCANTI, L. et al. (org.) Dicionário crítico de migrações internacionais. Brasília: Editora Universidade de Brasília, 2017.

DOMENACH, H. Sobre la "migratología”. In: Notas de población. V. 26, n. 6768, 1998, p. 101-118.

DUPAS, E.; BOTELHO, T. R.; ROMERO, T. G. A NOVA LEI DE MIGRAÇÃO E O VETO À LIVRE CIRCULAÇÃO DE POVOS INDÍGENAS E POPULAÇÕ̃ES TRADICIONAIS TRANSFRONTEIRIÇAS. In: Anais do XIV Congresso Internacional de Direitos Humanos. 2017. Disponível em http://cidh.sites.ufms.br/mais-sobre-nos/anais/.

GAUDEMAR, J. P. Mobilidade do trabalho e acumulação do capital. Lisboa: Editorial Estampa, 1977.

HAESBAERT, R. O mito da desterritorialização: do "fim dos territórios" à multiterritorialidade. Rio de Janeiro: Bertrand Brasil, 2012.

HARVEY, D. A produção capitalista do espaço. São Paulo: Annablume, 2005.

HARVEY, D. O novo imperialismo. São Paulo: Edições Loyola. 2004.

HARVEY, D. Os limites do capital. São Paulo: Boitempo, 2013.

HEIDEMANN, H. D. Deslocamentos populacionais e mobilidade fictícia: a razão fetichizada do migrante e do seu pesquisador. In: SILVA, S. A. (Org.). Migrantes em contextos urbanos: uma abordagem interdisciplinar. Manaus: FAPEAM, EDUA, 2010.

IANNI, O. $\underline{\text { A era do globalismo. }} 5^{\circ}$ Edição. Rio de Janeiro: Civilização brasileira, 2001.

KLUCK, E. G. J. O trabalho vai para o brejo: mobilização, migração e colapso da modernização. Dissertação (Mestrado). Universidade de São Paulo. São Paulo, 2011.

LEITE, A. C. G. L.; GIAVAROTTI, D. M.; KLUCK, E. J. G.; BOECHAT, C. A.; TOLEDO, C. A.; A MOBILIDADE REVISITADA: CAPITAL, TRABALHO E SUBJETIVAÇÃO. In: Geografares, Revista do Programa de Pós-Graduação em Geografia e do Departamento de Geografia da UFES. p. 5-21. Julho-Dezembro, 2017.

LUSSI, C. Teorias da mobilidade humana. In: DURAND, J.; LUSSI, C.

Metodologia e teorias no estudo das migrações. Jundiaí: Paco Editorial, 2015. p. 43-116.

MASCARO, A. L. Estado e forma política. São Paulo: Boitempo, 2013. 
MASSEY, D. S. et al. Worlds in motion: Understanding international migration at the end of the millennium. Oxford/New York: Oxford University Press, 2005.

ORGANIZAÇÃO INTERNACIONAL PARA AS MIGRAÇÕES (OIM). Glossário sobre migração. $\mathrm{n}^{\circ}$ 22. 2009. Disponível em:

<https://publications.iom.int/system/files/pdf/iml22.pdf> Acesso em: 1 junho 2020.

OLIVEIRA, A. T. R. Algumas abordagens teóricas a respeito do fenômeno migratório. In: OLIVEIRA, L. A. P. \& OLIVEIRA, A. T. R. (org.) Reflexões sobre os deslocamentos populacionais no Brasil. Rio de Janeiro: IBGE, 2011.

OLIVEIRA, A. Território e mercado de trabalho: Discursos \& teorias. São Paulo: Editora UNESP, 2006.

PELIANO, J. C. Acumulação de trabalho e mobilidade do capital. Brasília: Editora Universidade de Brasília, 1990.

PEREIRA NETO, C. Estudo migratório e teoria econômica neoclássica: equívocos e acertos de classificação. Terra Livre, v. 1, n. 52, p. 474-496, jan.jun./2019.

PERPETUA, G. M.; THOMAZ JUNIOR, A. Trabalho vivo no deserto verde: Mobilidade espacial da força de trabalho na produção de celulose e papel em Três Lagoas/MG. In: THOMAZ JUNIOR, A. et al. Geografia E Trabalho No Século XXI. Presidente Prudente: Centelha, 2004.

PORTES, A. Immigration theory for a new century: some problems and opportunities. In: International migration review. v. 31, n. 4, 1997, p. 779-825.

PÓVOA NETO, H. Migrações internas e mobilidade do trabalho no Brasil atual: novos desafios para a análise. Revista Experimental, n. 2, pp. 11-24, março 1997.

PÓVOA NETO, H.; FERREIRA, A. P. (org.) Cruzando fronteiras disciplinares: um panorama dos estudos migratórios. Rio de Janeiro: Revan, 2005.

REIS, R. R. Políticas de imigração na França e nos Estados Unidos (1980-1998). São Paulo: Hucitec, 2007.

SALIM, C. A. Migração: o fato e a controvérsia teórica. In: ENCONTRO NACIONAL DE ESTUDOS POPULACIONAIS, Anais, vol. 3, Campinas: ABEP, 1992, pp. 119-144.

SILVA, I. C. A. A mobilidade do trabalho sob o impacto da reestruturação produtiva: estudo das tendências migratórias em Santo André. Dissertação (Mestrado). Universidade de São Paulo. São Paulo, 2008.

SILVA, S. A. (org.) Migrações na Pan-Amazônia: fluxos, fronteiras e processos socioculturais. São Paulo: Hucitec; Manaus: Fapeam, 2012.

SINGER, P. Economia Política da Urbanização. 1. ed. São Paulo: Brasiliense, 1973.

SINGER, P. Economia Política da Urbanização. 14. ed. São Paulo: Contexto, 1998. 


\section{Discussão sobre as diferentes abordagens teóricas para o estudo das migrações e da mobilidade do trabalho}

SOARES, A. G. O Brasil na Irlanda: vidas em deslocamento na mobilidade contemporânea. Dissertação (Mestrado). Universidade de São Paulo. São Paulo, 2014.

TELES, L. J. S. Modernização e mobilidade do trabalho: Migrantes qualificados como tecnocratas do Estado em Porto Velho, Rondônia (1990 a 2012). Dissertação (Mestrado). Universidade de São Paulo. São Paulo, 2014.

VAINER, C. B. Deslocamentos compulsórios, restrições à livre circulação: elementos para um reconhecimento teórico da violência como fator migratório. In: XI Encontro Nacional de Estudos Populacionais da ABEP. 1998.

VALENCIA, A. S. Neo-imperialismo, dependência e novas periferias na economia mundial. In: SANTOS, T.; SADER, E. (Coord.); MARTINS, C. E.; VALENCIA, A. S. (Orgs.). A América Latina e os desafios da globalização. São Paulo: Boitempo, 2009.

ZLOTNIK, H. Théories sur les migrations internationales. In: CASELLI, G; VALLIN, J; WUNSCH, G. (eds.). Démographie: analyse et synthèse. IV. Les determinants de la migration. Paris: Editions de l'Institut National d'Etudes Démographiques, 2003, p. 55-78.

Recebido em 3 de junho de 2020

Aceito em 3 de agosto de 2020 